4. Gurbel PA, Bliden KP, Logan DK, Kereiakes DJ, Lasseter KC, White A, et al. The influence of smoking status on the pharmacokinetics and pharmacodynamics of clopidogrel and prasugrel: the PARADOX study. J Am Coll Cardiol 2013:62:505-12

5. Gagne JJ, Bykov K, Chowdry NK, Toomey TJ, Connolly JG, Avorn J. Effect of smoking on comparative efficacy of antiplatelet agents: systematic review, meta-analysis, and indirect comparison. BMJ 2013;347:f5307.

6. Cao C, Indraratna P. Ang SC, Manganas C, Park J, Bannon PG, et al. Should clopidogrel be discontinued before coronary artery bypass grafting for patients with acute coronary syndrome? A systematic review and meta-analysis. J Thorac Cardiovasc Surg 2014;148:3092-8

7. Ye Y, Xie H, Zhao X, Zhang S. Smoking and prasugrel. Int J Cardiol 2013:168:1590-1.

8. van Werkum JW, Heestermans AA, Zomer AC, Kelder JC, Suttorp MJ, Rensing BJ, et al. Predictors of coronary stent thrombosis: the Dutch Stent Thrombosis Registry. J Am Coll Cardiol 2009;53:1399-409.

\section{Preoperative investigations}

As an anaesthetist, I read the article 'Preoperative assessment: a cardiologist's perspective' (Aust Prescr 2014;37:188-91) with much interest. The statement that 'risk assessment before surgery aims to minimise potential perioperative complications is likely correct, although there is regrettably little evidence to substantiate this claim. However, I dispute the authors' view that for emergency surgery 'preoperative assessment uncommonly alters the course or outcome'.

The 2014 American College of Cardiology/American Heart Association guidelines recommend that, even for emergency surgery, clinical risk stratification should be undertaken, and that patients' morbidity and mortality risk can be estimated with the use of validated tools (www.riskcalculator.facs.org and www.riskprediction.org.uk/pp-index.php). Discussion of morbidity and mortality risk enables shared decision making, including the possibility that patients may decline surgery.

High-risk surgical patients have been described as those with a predicted postoperative mortality of greater than 5\%.' A 2011 report from the UK National Confidential Enquiry into Patient Outcome and Death suggests that high-risk surgical patients should be carefully considered for postoperative high-dependency or intensive care. ${ }^{2}$

Disturbingly, in Australia (unlike New Zealand) good data on system-wide postoperative mortality are not collected and publicly reported. Clearly, not all postoperative morbidity and mortality is cardiac.

\section{Joanna Sutherland}

Conjoint associate professor, UNSW Rural Clinical School VMO Anaesthetist, Coffs Harbour Health Campus Coffs Harbour, NSW

\section{REFERENCES}

1. Pearse RM, Harrison DA, James P, Watson D, Hinds C, Rhodes A, et al. Identification and characterisation of the high-risk surgical population in the United Kingdom. Crit Care. 2006;10:R81

2. Findlay GP, Goodwin APL, Protopapa K, Smith NCE, Mason M. Knowing the risk: a review of the peri-operative care of surgical patients. London: National Confidential Enquiry into Patient Outcome and Death; 2011.

\section{Austin Ng and Leonard Kritharides, the authors of} the article, comment:

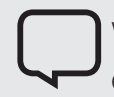

We stand by our statement that 'for emergency non-elective surgery, preoperative risk assessment uncommonly alters the course or outcome of the operation as the urgency of the surgery takes precedence'. However, we did not intend for the statement to suggest not conducting preoperative assessments for emergency non-elective surgery. As stated by Dr Sutherland and in our article, 'identifying highrisk conditions such as class IV congestive heart failure, unstable coronary syndromes, or severe valvular heart disease (by conducting a preoperative assessment) can impact upon perioperative and postoperative management' from a cardiologist's perspective. Moreover, we agree that using validated surgical risk assessment tools will identify other non-cardiac high-risk factors. An appropriate risk assessment can then be presented to the patient or relatives for an informed decision. More research is clearly needed as the evidence behind preoperative assessment remains poor.

\section{Data informs debate}

The editorial 'Data informs debate' (Aust Prescr 2015;38:38-9) describes the uncertainties around the efficacy and safety of new medicines entering the market. It outlines the role that increased access to clinical trial data may have in informing assessments about the appropriate place of new drugs in clinical practice.

Just as it is important to consider new drugs, it is also important to consider the use of currently available drugs in new markets, or new populations. Populations vary, for a variety of reasons, in their response to specific drug therapies.,2

Australia has a unique population in its Aboriginal and Torres Strait Islander people. This population may not have been included in clinical trials, so further analysis of trial data will often not be informative. Substantial uncertainty exists regarding 
the safety and efficacy of medicines in Aboriginal and Torres Strait Islander people, despite their need for extensive use of medicines to manage the high burden of disease.

It is important that Australian prescribers are aware of the limitations of drug safety and efficacy data for Aboriginal and Torres Strait Islander people. Clinicians are encouraged to publish their own observations, including reporting adverse drug reactions, to the Therapeutic Goods Administration. These observations are essential to inform robust assessment of medicines for Australia's indigenous populations. ${ }^{3-6}$

Genevieve Gabb

Physician

Repatriation General Hospital

Daw Park, SA

Agnes Vitry

Pharmacist

University of South Australia
Tilenka Thynne

Physician

Pharmacology

Flinders University

Adelaide

\section{REFERENCES}

1. Miller DR, Oliveria SA, Berlowitz DR, Fincke BG, Stang P, Lillienfeld DE. Angioedema incidence in US veterans initiating angiotensin-converting enzyme inhibitors. Hypertension 2008:51:1624-30.

2. Hippisley-Cox J, Coupland C. Individualising the risks of statins in men and women in England and Wales: population-based cohort study. Heart 2010:96:939-47.

3. Gabb GM, Vitry A, Limaye V, Alhami G. Serious statin associated myotoxicity and rhabdomyolysis in Aboriginal and Torres Strait Islanders: a case series. Intern Med J 2013;43:987-92

4. Mahajan H. Thynne T, Gabb GM, Poh EW. Drug safety in Aboriginal Australians: three cases of angiotensinconverting enzyme inhibitor angioedema. Intern Med J 2015:45:231-3.

5. Harding DJ, Subramaniam K, MacQuillan G, Davis J, Nolan D. Severe drug-induced hypersensitivity syndrome with a shared HLA-B allele. Med J Aust 2012;197:411-3.

6. Haysom L, Samaras K, Stapylton C, Wines J. Statin associated myotoxicity in an incarcerated Indigenous youth - the perfect storm. Med J Aust 2015:202:381-2.

\section{Book review}

\section{Psychopharmacology and pregnancy}

\section{Rebecca Hill}

Consultant psychiatrist Women's and Children's Health Network

Adelaide
Megan Golbaly- Martiea Socllen Medrem teatio farmon

Psychopharmacology and Pregnancy

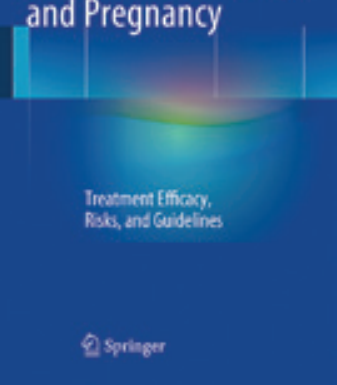

\section{Galbally M, Snellen M, Lewis A}

Heidelberg: Springer-Verlag Berlin Heidelberg; 2014. 223 pages

The editors of this book undertook to provide an overview of the current state of knowledge concerning the use of psychotropic medication in pregnancy, with a second stated aim of producing clinical guidelines for practitioners. The historical reluctance to include pregnant women in research, and the need to consider the interests of both mother and baby, makes this a Herculean task. Here, the task is well-accomplished, with noted researchers from the field presenting us with an excellent and concise summary.

The initial chapters set out the unique challenges in perinatal mental health, an understanding of which is essential when counselling a pregnant woman about the options available to her. These include the ethics of informed consent and the difficulties of interpreting a flawed evidence base. They also include explanations of how the interaction of maternal, fetal, genetic and environmental factors may mediate the effects on babies of perinatal exposure to maternal mental illness and associated medicines.

Later chapters consider in turn the major categories of perinatal mental illness, in most cases providing itemised guidelines for clinicians at their conclusion. A minor criticism is that the presentation of these guidelines varies between chapters. This tends to reduce the ease of use of the book as a 'quick reference guide'.

More difficult topics such as borderline personality disorder, eating disorders and substance abuse have been included. There is a chapter on the impact of popularly used complementary and alternative treatments. Another deals with the use of ECT, a treatment with high efficacy from which pregnant women may find themselves unfairly excluded.

Clinicians unfamiliar with the topic will be able to find some quick, wise pointers by turning immediately to the guideline sections. Those seeking a deeper understanding of the literature will also be rewarded. 